\title{
Identidades transnacionales e imaginación desbordada, en dos textos del narrador ecuatoriano Esteban Mayorga
}

\section{Transnational identities and overflowing imagination, in two texts of the Ecuadorian narrator Esteban Mayorga}

DOI: https://doi.org/10.29166/tyc.v1i19.2073

\begin{abstract}
Martha Rodríguez Albán
Licenciada en Ciencias de la Educación, con mención en Lengua y Literatura (Universidad Técnica Particular de Loja); Magíster en Estudios de la Cultura (UASB-Ecuador), magíster en Ciencias Sociales (FLACSO-Ecuador); PhD en Literatura Latinoamericana (UASB-Ecuador). Ha publicado: Narradores ecuatorianos de 1950: Poéticas para la lectura de modernidades periféricas (2009), y Cultura y política en Ecuador: estudio sobre la creación de la Casa de la Cultura (2015). Mantiene inéditos los trabajos "Crítica literaria y sociedad. Ecuador, 1930-2000", y su tesis doctoral "Pasillo ecuatoriano, radio e industrias culturales, 1920-1965: disputas por el mercado de la música y el poder simbólico en el campo cultural". Docente de Teorías de la Cultura en la Facultad de Comunicación Social de la Universidad Central del Ecuador.
\end{abstract}

Correo:m1rodriguez@yahoo.com

\section{Resumen}

El presente artículo estudia dos libros del narrador ecuatoriano Esteban Mayorga (Quito, 1977); en el análisis, pone en diálogo dichos textos con perspectivas sociológicas de la Teoría de la Globalización. La autora sostiene que, Un cuento violento (2008) y Vita frunis (2010), ejemplifican dos categorías sociológicas vinculadas con los temas de las migraciones y la globalización; en los textos se apreciaría lo que Vertovec denomina "prácticas transnacionales de intercambio y comunicación"; asimismo, existe un narrador que enuncia claramente desde la "bifocalidad". Finalmente, Mayorga reflexiona también sobre las reconfiguraciones de identidad en campos sociales transnacionales.

Palabras clave: narrativa ecuatoriana, posmodernidad literaria, identidades transnacionales, imaginación desbordada, campos sociales transnacionales.

\section{Abstract}

This article studies two books of the Ecuadorian narrator Esteban Mayorga (Quito, 1977); in the analysis, he puts these texts in dialogue with sociological perspectives of the Theory of Globalization. The author holds that $A$ violent story (2008) and Vita Frunis (2010), illustrate two sociological categories linked to the issues of migration and globalization; the texts would appreciate what Vertovec calls "transnational practices of exchange and communication"; there is also a narrator who clearly states from the "bifocality". Finally, Mayorga also reflects on identity reconfigurations in transnational social fields.

Keywords: ecuadorian narrative, literary postmodernity, transnational identities, overflowing imagination, transnational social fields. 
Desde un punto de vista sociológico, la literatura es una práctica inscrita en un campo social, que contribuye a modelar percepciones y narrativas relacionadas con las identidades. Estos modelamientos han tenido lugar en escenarios de disputas y tensiones, en diferentes momentos históricos. Si el filósofo Eduardo Devés Valdés plantea que "el pensamiento latinoamericano desde comienzos del siglo XIX ha oscilado entre la búsqueda de modernización o el reforzamiento de la identidad", (2000, p. 15) podría decirse lo mismo de las búsquedas específicamente literarias. En efecto, desde las décadas finales del siglo XIX, tendió a focalizarse el valor de la literatura latinoamericana en relación a sus aportes para la configuración o reforzamiento de las identidades en relación con espacios geográficos, tendiéndose a circunscribir su impacto dentro de los límites nacionales y regionales. En el presente ensayo analizo, a partir de un estudio de caso (textos del ecuatoriano Esteban Mayorga), las posibilidades de mirar a la literatura como una "práctica transnacional de intercambio y comunicación”, (Vertovec, 2004, p. 974) que mantiene su incidencia en las reconfiguraciones identitarias a partir de las representaciones de migrantes y comunidades transnacionales que puede brindar.

Conocí la narrativa corta de Esteban Mayorga en 2010, mientras escribía una ponencia para el XI Encuentro sobre Literatura Ecuatoriana Alfonso Carrasco Vintimilla (Cuenca, octubre de 2011). Allí analizaba los libros de cuentos ganadores del Premio Nacional Joaquín Gallegos Lara entre 1990 y 2010, y sus- tenté que ellos adscribían a tres estéticas: textos modernos del realismo abierto, textos posmodernos del realismo fantástico y textos posmodernos de estéticas heterogéneas. Entre estos últimos - cuatro, en total - se encontraba Un cuento violento, de Esteban Mayorga (Quito, 1977). Como contexto, planteé que en los años 80 y 90 se evidenciaron diversas crisis sociales y se apreció la emergencia nuevos paradigmas; en literatura, en esos años aparecieron obras que pueden signarse como posmodernas. En dicha ponencia, yo sustentaba que el texto de Mayorga mostraba rasgos de lo que se conoce como posmodernismo en literatura. (Rodríguez, 2011, p. 3-4) Esa categoría

agrupa a obras que implican autoreflexividad y la parodia irónica, (Hutcheon, 1998: 11) que 'prefiere[n] el montaje a la perspectiva, la intertextualidad a la referencialidad, el 'pieza por pieza' a las totalidades unificadas. Se regocija[n] excesivamente con el juego, el jolgorio, la asimetría y hasta el desbarajuste; en suma, con la emancipación de los sentidos de sus ataduras a la mera realidad adocenada'. (Hartley, 1995: 276) Uno de los rasgos clave para comprender la poética de los posmodernistas es su renuncia o rechazo de 'todo intento de llegar a una explicación global del proceso colectivo histórico o social'; (Shaw, 2003: 376.) en su defecto, buscan la postulación de ‘una crisis'. (Ibíd.)

En diálogo con ese trabajo, en el presente ensayo ampliaré la mirada sociológica a sus escritos, al revisar los dos libros de Mayorga: Un cuento violento (2008) y la novela Vita frunis (2010) ${ }^{1}$, que no estudié en la ponencia de 2011. Mi propuesta

1 El primer libro obtuvo el Premio Joaquín Gallegos Lara, de cuento, en 2008; el segundo, el Premio Nacional de novela Pablo Palacio, convocado por el Ministerio de Cultura del Ecuador, en 2009. 
es que la literatura de Esteban Mayorga muestra rupturas con la de los restantes narradores ecuatorianos de entresiglos en los siguientes aspectos: se presenta como una "práctica transnacional de intercambio y comunicación", (Vertovec, 2004, p. 974) muestra a un narrador que se enuncia desde la bifocalidad, y reflexiona sobre las reconfiguraciones de identidad en campos sociales transnacionales. Aunque eran cuatro los narradores que cultivaban estéticas posmodernas, solo el texto de Mayorga permitía apreciar, en sus personajes, las reconfiguraciones identitarias en contextos transnacionales, así como un trabajo desde la bifocalidad. De hecho, es el único de los cuatro mencionados $-\mathrm{y}$ de todo el conjunto de dieciocho narradores ecuatorianos de entresiglos - que es migrante. Por esta razón, además de sus méritos literarios sin discusión, lo he elegido para el presente estudio de caso.

Empleo en este ensayo la categoría de campo social, planteada por Peggy Levitt y Nina Glick Schiller, para estudiar las relaciones sociales en contextos transnacionales. Esta categoría supera la idea de que las sociedades se determinan y circunscriben principal o exclusivamente dentro de los límites del estado-nación ${ }^{2}$. Campo social es, entonces,

un conjunto de múltiples redes interconectadas de relaciones sociales, a través del cual las ideas, prácticas y recursos se intercambian, organizan y transforman de manera desigual. [...] Los campos sociales son interacciones estructuradas, abarcadoras y multidimensionales, que tienen diferente forma, profundidad y amplitud, y que son diferenciadas, en la teoría social, em- pleando términos como organización, institución y movimiento social”. (Levitt y Glick Schiller, 2004, p. 1009)

$\mathrm{Al}$ desplazar la definición del continente espacial y centrarla en las redes de relaciones sociales - en las interacciones estructuradas-, es posible reconocer la existencia de campos sociales nacionales y campos sociales transnacionales. (Levitt y Glick Schiller, 2004, p. 1009) Adicionalmente, las autoras resaltan las diferencias entre maneras de estar en un campo social y de pertenecer a él. Las maneras de estar son las prácticas de los individuos, sus relaciones con personas, instituciones y organizaciones, las experiencias que viven en su campo social; son prácticas, vínculos y experiencias que no siempre, ni necesariamente, se acompañan de sentimientos de pertenencia. Estos sí existen cuando los individuos o grupos realizan "acciones concretas y visibles que marcan pertenencia, tales como usar una cruz cristiana, una estrella judía, ondear una bandera o elegir una particular cocina. Las maneras de pertenecer unen acción y conciencia del tipo de identidad que tales acciones significan." Concluyen las autoras que "los individuos en campos sociales transnacionales combinan maneras de estar y maneras de pertenecer de manera diferenciada, en contextos específicos". (Levitt y Glick Schiller, 2004, p. 1010)

El primer elemento que diferencia a Mayorga de los restantes narradores estudiados es su trabajo (su ejercicio de auto-construcción) como escritor, que puede leerse como una "práctica transna-

2 Nacionalismo metodológico es la tendencia a aceptar "el estado-nación y sus fronteras como algo dado, en el análisis social”. (Levitt y Glick Schiller, 2004, p. 1007) 
cional de intercambio y comunicación”. El antropólogo social Steven Vertovec resalta la influencia de la vida transnacional sobre las vidas diarias de los migrantes y de las personas de los países de origen: “"el surgimiento de unas prácticas sociales transnacionales y de instituciones [...] crea un campo de sociabilidad e identificación entre inmigrantes y las personas del país de origen'. (Itzigsohn and Saucido, citados por Vertovec, 2004, p. 973) Me parece que el ejercicio de escritores migrantes, como es el caso de Esteban Mayorga, puede ser leído también como otra de estas prácticas transnacionales, que se inscribe en campos de sociabilidad e identificación. La influencia sería dialéctica, entre él y los miembros del campo literario específico, así como con aquellos del campo social, más amplio. En este sentido, si bien el escritor está realizando su carrera en EE.UU., mantiene una conciencia de lo que otros escriben en el país de origen, y desea ponerse en diálogo y en discusión - a partir de sus propios textos- con otros escritores del campo literario local.

Todos los textos [literarios] que he publicado los he producido acá, y creo que el único medianamente importante sería mi novelita [Vita frunis]. Digo esto porque, espero que resulte incómoda y suponga una fisura, no la ruptura en el sentido estricto de la vanguardia y "lo nuevo", porque de original no tiene nada (Roussel, Copi, Pynchon, Aira por citar ejemplos), sino una fisura en el sentido de darse cuenta de que hay una narrativa o un discurso agotados en un contexto específico, y que tal vez es saludable explorar otras sendas. (Mayorga, 2012)

El escritor se está construyendo a sí mismo en un diálogo entre sus textos y los de otros / de sus pares. Se está constru- yendo en una experiencia de simultaneidad, la cual implica "vivir vidas que incorporan actividades diarias, rutinas e instituciones localizadas tanto en un país de destino como transnacionalmente". (Levitt y Glick Schiller, 2004, p. 1003) En efecto, trabaja (en su oficio de escritor) y estudia en el país de destino, pero mantiene lazos transnacionales con las comunidades literaria y no literaria del país de origen. Esos lazos se fabrican y manifiestan en su diario oficio de narrador. Busca el diálogo con este público, y no lo oculta; al contrario, vuelve explícita la presencia del lector imaginario, cuando sostiene que, al escribir, generalmente "uno tiende a pensar en el público donde el texto será publicado". (Mayorga, 2012) Otra muestra del diálogo que se quiere entablar es el haber editado sus dos libros en Ecuador, luego de haberlos enviado a concursos nacionales. Pero los movimientos se producen también en sentido inverso: el que esos libros hayan sido premiados alude a una incidencia en el campo literario local; se puede pensar ya en una influencia mutua: lo que hace un autor premiado empieza a volverse modelo para algunos narradores jóvenes; en todo caso, produce una suerte de mínimo temblor en el canon literario nacional, en el peor de los casos. Todo esto puede considerarse y estudiarse como otra más de las "prácticas transnacionales de intercambio y comunicación" que menciona Vertovec, creadoras de campos de identificación para el migrante y para los habitantes del país emisor.

El escritor ha dado un paso mayor de anclaje en "la ancha banda limítrofe" del espacio social transnacional, al insertarse en las mencionadas instituciones literarias. No solo ha ganado mayor capital cultural, sino que ha conseguido instalar 
su trabajo y su nombre en el canon -que es otro constructo, sí, pero también una institución de enorme peso-, avalado por los premios obtenidos en concursos literarios nacionales. $\mathrm{Al}$ respecto, la noción de conexiones establece una distinción clave entre situaciones de simple comunicación, y otras que implican vínculos fuertes, de carácter institucional, en más de un estado-nación. Levitt y Glick Schiller dicen, sobre las conexiones: "uno puede tener amigos, colegas o co-religionarios con quienes nos comunicamos e intercambiamos objetos a través de fronteras, sin entrar nunca en contacto con ese otro Estado $\mathrm{u}$ otras instituciones. Pero si pertenecemos a una Iglesia, recibimos una pensión o realizamos inversiones, [...] nuestro 'pivote' está anclado en dos o más sistemas legales y regulatorios, estimulando un mayor sentido de incrustación en el campo social transnacional y volviendo más duraderas las conexiones en él." (Levitt y Glick Schiller, 2004, p. 1012) Esteban Mayorga formó parte del sistema académico estadounidense (como alumno de un programa de doctorado, y como profesional), y también se está insertando en la institucionalidad literaria del Ecuador.

Pero las filiaciones institucionales son maneras de estar, no necesariamente maneras de pertenecer. En cuanto a sus vínculos afectivos, el escritor es estudiante regular de la Universidad de Boston, donde cursa su doctorado en Literatura, en efecto; pero no tiene relaciones de pertenencia con ésta ni con ninguna de las cuatro universidades en que ha estudiado, en Ecuador y en EE.UU.; no lo atan la Academia, ni sus redes de poder. Su pertenencia - lo ha dicho- está del lado del ejercicio como escritor. Sus lazos afectivos transnacionales son familiares, de amistad y de orden cultural (con las instituciones y la crítica literaria local, que es también una institución); a través de estos vínculos él se reafirma como parte de la comunidad transnacional de escritores y lectores de Ecuador y de la región. Estos vínculos generan expectativas en él (que "no son románticas ni horripilantes"): sabe que pertenece "a la tradición literaria del Ecuador, lo quiera o no, y eso no es ni malo ni bueno, sino un azar." (Mayorga, 2012) Lo importante para él es ser escritor, estar en diálogo con sus pares; tiene claro $-\mathrm{y}$ lo manifiestaque su más fuerte identidad es ésta, la que se juega en la literatura. Los acercamientos con instituciones culturales del país y su confesada preocupación por la escritura, dejan en claro cuál es su verdadera pertenencia: "toda la energía toda, todo el esfuerzo todo, desde de mañanita hasta de noche, debe estar en leer y escribir cada vez mejor.” (Mayorga, 2012)

En cuanto al tema de la identidad, la construcción narrativa de su propia vida (que realiza Esteban Mayorga), por un lado, y los posicionamientos de los narradores de sus historias y los de sus personajes, por otro, pueden ser vistos como dos niveles de referencialidad que se mezclan e influyen mutuamente, y que contribuyen a las reconfiguraciones identitarias en la modernidad desbordada: la que toca al autor y a sus lectores transnacionales. "Las experiencias que están en [mis] textos son todas ficticias aunque en ocasiones puedan tener un referente que en el imaginario sea 'real'. La cosa es no saber cuál es cuál y habitar ese umbral: para mí es más valioso morar en la frontera”: (Mayorga, 2012) así se construye el escritor Esteban Mayorga: en sus propios textos, en la ancha frontera entre realidad e imaginación, en la vida transnacional y en la escritura. 
Aún cercana a las reflexiones de Vertovec, paso a la segunda diferencia entre los textos de Esteban Mayorga y los del resto de escritores ecuatorianos de entresiglos, estudiados en la ponencia. Quiero analizar el hecho de que, en varios de sus cuentos y en su novela, muestra narradores que se enuncian desde la bifocalidad. Ya no me refiero al escritor llamado Esteban Mayorga, sino a un constructo literario: la función "narrador", que relata o presenta las historias en esos textos. Por otro lado, al analizar desde la bifocalidad, se ha modificado el punto de vista: este concepto ya no hace énfasis en las estructuras (nivel macro del análisis), sino en las subjetividades, el pensamiento y el comportamiento cotidianos de los "sujetos transnacionales" (nivel micro).

La bifocalidad es una herramienta conceptual que nos aproxima a "las subjetividades, las motivationes, significados y el lugar de las personas como agentes del cambio" de sus propios mundos sociales, con la mediación o en el contexto de la vida transnacional. (Vertovec, 2004, p. 973974) Llamado también "marco de referencia dual", "habitus del transnacionalismo migrante", el concepto de bifocalidad hace referencia a la condición cognitiva y emocional que relaciona "de manera simultánea e inextricable el aquí y el allá del migrante transnacional. (Cfr. Vertovec, 2004, p. 975) Los sentidos imputados al aquí (la prosperidad o la seguridad económica que el migrante fue a buscar), y al allá (sentimientos y vínculos identitarios individuales y sociales, así como con la espiritualidad, atribuidos al país de origen), pueden desplazarse en variadas y cambiantes configuraciones, para los migrantes transnacionales.

Comenzaré con el análisis del narrador de Vita frunis. La bifocalidad es uno de los elementos que llama primero la atención en esta novela: en el discurso del narrador y en la sintaxis de Fruno, como personaje. Es un estadounidense, sin embargo, y no un migrante transnacional. Este personaje se convierte luego en escritor, pero son claras sus distancias y disputas con la academia y el status quo. Dicho sea de paso, la posición del narrador de varios cuentos del primer libro de Mayorga, es similar: desconfiando del reconocimiento canónico, concediendo a la literatura, como único valor, el placer que otorga con la lectura y con el oficio de escribir.

Respecto de la bifocalidad del narrador, es interesante el planteamiento de que las naciones y sus límites no desaparecen para el individuo: más bien mira la nación, la vive y se relaciona con ella de otra manera. El narrador escribe para un público ecuatoriano, ciertamente (de manera continua le lanza miradas cómplices: con la mención de comidas u objetos muy arraigados en las costumbres de los ecuatorianos, el empleo de expresiones como "ichugcha!" y muchas otras frases). Pero no es en absoluto un texto principal o exclusivamente dirigido a ecuatorianos: se ambienta en EE.UU. (en Turpento y en Boston, ciudad que le representa para el narrador un amor contradictorio: habla su gente, sus parques, sus problemas de estacionamiento); se desplazan por carreteras estadounidenses, polemiza sobre lo discriminatorio del acceso a las tarjetas verdes; retrata a empleados de tiendas, bibliotecas y hospitales estadounidenses; realiza comentarios sobre el presidente de EE.UU., sobre los mormones. Y, a pesar de todo ello, tampoco es un texto principal o exclusivamente dirigido a estadounidenses. Se trata, me parece, de un narrador claramente anclado en la bifocalidad, con un aquí y un allá completamente resignifica- 
dos, acaso incluso indiferenciados en algunos momentos, contribuyendo a la configuración de la comunidad de sentimientos de la que se hablará más adelante.

Aún hay más, sobre el marco de referencia dual de Fruno. Si bien él no es migrante, muchos de los personajes con quienes se relaciona sí lo son; varios de ellos no tienen documentos en regla y -al igual que muchos otros nacidos en EE.UU., con quienes también se cruzadesempeñan actividades al margen de la ley. Fruno, como narrador, describe así a un ecuatoriano, que luego le vende algo de enorme carga simbólica: una cédula de identidad falsa.

Conversamos más rato y el ecuatoriano histriónicamente hablaba para no callarse jamás, hablaba de su país todo el tiempo y no daba cabida a rupturas o descansos, cosa que daban ganas de acometerle a golpes; y entre otras cosas habló del Ruiseñor de América, de las playas y alturas, de un tal César Verduga que era su pariente, de un pueblo llamado Patate, del veneno para ratas Racumín, de un lugar llamado la Casa del Amortiguador, de una tal Marián, de la Óptica Chacón que era de su tía, de un tal licenciado Duplein, de las cocinetas Hotpoint, de comidas varias como ceviche de concha, hallullas, granizados, espumillas, frunas, canguil, empastados, aplanchados, bebas, pinol, colada morada y nimiedades de diversa índole que a mí me mataron del aburrimiento. (Mayorga, 2010, p. 26)

En otro momento, reaparece este personaje, con su amigo mexicano. El ecuatoriano lleva su identidad a cuestas, y ella lo tortura, según la perspectiva de Fruno:

[...] Durante el recreo compré unas papas fritas y el ecuatoriano, el mexicano y yo, conversamos. El ecuatoriano dijo:

-Sabes que yo en el Ecuador soy conocidazo primero porque soy buen puñete, la gente me conoce como el mejor puñete de Quito; segundo porque tengo un bar al cual solo entramos los selectos; tercero porque soy el campeón nacional de enduro y tengo una KTM.

-No jodas, fascinante, respondí.

Después el ecuatoriano sacó un sándwich de atún de una funda de plástico y después sacó otra funda de plástico y un sorbete; le pregunté que qué llevaba en la segunda funda.

-El jugo, me respondió.

Me percaté que el ecuatoriano traía su Ecuador metido y pudriéndole el cuerpito. (Mayorga, 2010, p. 60-61)

Al igual que ocurrió con el trabajo del lenguaje, podría decirse que el narrador de Vita frunis realiza una suerte de síntesis identitaria: funda para sí una identidad transnacional, desde cuyo centro realiza aproximaciones intensas y distanciamientos entre ambos "polos identitarios", sufriendo y gozándolos a ambos sin anclarse en ninguno, deconstruyendo sus esencias, hibridándolos.

El estadounidense Fruno habla como ecuatoriano, pero no es el único. En los dos libros de Mayorga, buena parte de los personajes extranjeros y migrantes se expresan y comunican empleando "ecuatorianismos": "Hans dijo simón loco y Mich dijo ya pues ñaño, en alemán”; (Mayorga, 2008, p. 11) pululan frases $y$ expresiones como "harás durar", "perro runa", "amigos de chupe”, “iJesusito!”, “iQué rica bestia!”, en personajes de diversas nacionalidades, y se leen con absoluta naturalidad.

Lo que llama la atención es que este lenguaje plagado de modismos de un país en particular resulte verosímil, tanto como la manera de pensar, sentir y de comportarse de dichos personajes. Acaso porque muchas particularidades culturales ahora nos resultan familiares, con las comunicaciones globalizadas. Acaso porque Fruno 
condensa un sustrato común, que vuelve posible que nos reconozcamos en él, en sentires y actitudes humanos. La comunidad de sentimientos a la que alude Appadurai (2001: 23) se conforma, precisamente, al socializar las experiencias, que dejan así de ser individuales o esencializadas, para transformarse en grupales, construidas, redefinidas: "parte de lo que los medios de comunicación de masas hacen posible [y también la literatura], precisamente a raíz de producir condiciones colectivas de lectura, crítica y placer, es lo que en otra oportunidad denominé comunidad de sentimientos [...], que consiste en un grupo que empieza a sentir e imaginar cosas en forma conjunta, como grupo." (Appadurai 2001, p. 23) En este caso, la abundancia de representaciones procedentes de diversas partes del planeta parece configurar no solo aquella comunidad de sentimientos, sino claves comunes de lenguaje; estas claves o resortes nos traen de regreso a sentimientos básicos, nos vuelven capaces de ser solidarios con desconocidos habitantes de las antípodas, nos sensibilizan para abrirnos y mirarnos en ellos: el trabajo de la imaginación, el trabajo del lenguaje, allí reunidos.

Un aspecto adicional (pero no menos importante) de la sintaxis del personaje Fruno tiene que ver con el oficio del escritor, tema común a sus dos libros. Este personaje mantiene una tensión cognitiva, centrada en un problema existencial; si bien banaliza y quita peso a su propia existencia, ésta cambia de curso mediante el trabajo de la imaginación, plasmado en la literatura. No se trata del antiguo "encontrar sentido a su vida, a través del arte”, pues la perspectiva del narrador respecto de "su historia personal" y de su literatura es desengañada, burlona, carnavalesca.
Desde ese punto de vista, él riza doblemente el rizo: en un primer nivel (el del narrador) se realiza la síntesis cultural; en un segundo nivel (la secuencia de eventos que configuran la vida del personaje) se presenta el trabajo de la imaginación para reconstruir la vida y la narrativa de la propia vida; ambivalencia y negociación entre realidad e imaginación; ambivalencia y negociación en la construcción identitaria.

Acaso el final de Vita frunis tiene algo de triste, en la medida en que Fruno "ahora escribe en serio", ha ganado reconocimiento, se ha casado: ¿es una nueva reconfiguración identitaria individual, o es que acaso ha plegado a los valores del mercado, que apuntan a cercarlo, a que renuncie a su autonomía, a regularlo a través de las instituciones literarias? El final es abierto, y no es posible saber si el personaje se mantiene en la resistencia.

Vertovec planteaba que "los trabajos [de la bifocalidad] son claramente discernibles en las prácticas sociales y transmitidos en las narrativas individuales". (2004, p. 977) En el caso que analizamos, se trata de unas narrativas que tienen un rasgo particular: son literarias. Y en ellas se realiza un trabajo orientado a los lectores orientado a los escritores. En efecto, a través de los personajes literatos, el narrador propone -implícita, y a veces explícitamente- su poética, su noción de lo literario, la función y el valor de la literatura en la vida de quien narra: eso la vuelve una novela en la que muchos escritores pueden encontrarse, o bien, con la que pueden discrepar; propone nociones que desacralizan la visión de la literatura como un arte de élites en el que ellas pueden verse reflejadas, una suerte de iluminación o una producción vinculada a (¿atrapada en?) la Academia. En cierto 
modo, democratiza la literatura: desde el juego irreverente, la retorna a sus raíces populares, ancladas en los márgenes sociales, acaso recordando la ironía, los excesos y el humor escatológico de Rabelais -noción de lo literario, por cierto, con la que ciertos sectores institucionalizados discreparon antes y siempre discreparán, rabiosamente-. Con este comentario cierro el planteamiento de que, en la línea de otras narrativas $-\mathrm{y}$ sin perder su carácter específico de arte y de oficio-, la literatura contribuye a reconfigurar (a base del trabajo de la imaginación) las percepciones y las narrativas-otras relacionadas con la habilitación de nuevos espacios sociales.

Finalmente, el tercer rasgo que diferencia a Mayorga de los restantes narradores de entresiglos es que, a través de sus personajes, reflexiona sobre las reconfiguraciones de identidad en campos sociales transnacionales. Según se comentó antes, Mayorga representa en sus libros la vida transnacional de emigrantes de México, Ecuador, Bolivia, China, EE.UU., Alemania, Bangladesh, etc., con énfasis en las subjetividades de estos personajes.

El sociólogo jamaiquino Stuart Hall nos recuerda la inserción histórica de toda tensión o disputa, al reflexionar sobre identidades. Se trata de complejos y conflictivos procesos que tienen lugar en contextos transnacionales; puede aspirarse muchas veces al equilibrio de la visión cosmopolita, pero se mantiene en el terreno inestable de la frontera: "para para la mayoría de nosotros, el cosmopolitismo ha implicado una relación continua con la cultura de nuestra familia. Uno [...] valora el momento en que los dejó, pero sabe que a medida que los deja ellos siguen siendo su apoyo. Continúan siendo lo que uno es. Uno no podría ser lo que es, sin esa lucha, tanto para defenderlos como para salir de ellos". (Hall, 2002, p. 30) Esta doble lucha se manifiesta con claridad en la configuración de varios personajes migrantes de los textos de Mayorga. Tomemos, por ejemplo, parte de un monólogo que consta en "La vida de Silvia Blanco", de Un cuento violento. Hija de mexicanos pobres (albañil y costurera), el personaje relata: "mis padres solo cruzaron la frontera para que yo naciera en EE.UU.”. (Mayorga, 2008, p. 64)

Yo, porque nací en Los Ángeles, era una ciudadana estadounidense, pero mi familia era toda mexicana así que les dije que me quedaba y no sé por qué les dije braceros infames (tuve un lapsus brutus). Y ahora que lo pienso, por tener esos benditos papeles creo que me sentía víctima perenne del ostracismo fruto de la envidia o solamente del propio ostracismo porque mis primos me decían lárgate al norte, mis compañeros de la escuela, lo mismo, mis compañeros de la prepa, lo mismo, mi hermano, lo mismo [...]. Pero yo les decía: no, a mí me encanta México y acá me quedo. Ahora me río de mí misma porque vivo acá (estoy escribiendo en mi dormitorio de la universidad en Salt Lake City) más de 7 años y no vuelvo a México ni aunque me paguen millones y me rueguen". (Mayorga, 2008, p. 67)

Resulta clara la oscilación, no exenta de contradicciones, entre el aquí y el allá, el antes y el ahora, el inglés y el español, los lapsus y los afectos. Es el inicio de las memorias de Silvia.

Stuart Hall pone énfasis en que la construcción de las identidades se realiza, ineludiblemente, en el lenguaje: "Precisamente porque las identidades se construyen dentro del discurso y no fuera de él, debemos considerarlas producidas en ámbitos históricos e institucionales específicos en el interior de formaciones y prácticas discursivas específicas, mediante estrategias enunciativas específicas”. (Hall, 2003 [1996], p. 18) Silvia 
Blanco escribe el relato de su vida, y en este ejercicio otorga sentido a los fragmentos de su historia; al reunirlos, ella construye su identidad -una representación, siempre mediada por el discurso-. Pero lo novedoso de este trabajo psíquico de la imaginación, es que en él se conjugan recuerdos e imágenes, paisajes y relatos, ficciones y vivencias de personas de otros países que ha conocido:

La primera vez [que viajé en avión] la recuerdo claramente, al lado mío había una rusa guapísima que leía un libro de turismo con tranquilidad y con un lápiz en su mano derecha. La rusa en contra de todo pronóstico hablaba un español que te mueres, es decir, impecable. La rusa parecía reportera y parecía una lindura y era una belleza, y yo asumo que era de lo más aventurera porque parecía que había viajado por todo el mundo. Me cayó muy bien y me dije Silvia Blanco tú vas a ser como la rusa y viajar y leer libros de viaje y volar en aviones". (Mayorga, 2008, p. 73-74)

El trabajo de la imaginación refuerza los propios sueños, los deseos de alejarse de la historia previa, de ser al fin aquella persona que uno soñó: "Y estas imágenes [...] me llevan a terminar mi relato y pensar en la marisma [del pueblo] y en que tengo una gran suerte porque ni las gaviotas, ni la Caballo Rápido, ni la rusa, ni la sangre, ni mi hermano el feo, ni el idioma, ni mi papá alcohólico, ni mi ojo, ni mi pobreza, ni nada ni nadie, ha podido disminuir mi interés y capacidad de escribir estas memorias y de soñar en ser doctora y de ser, por decirlo así, un ser maravilloso." (Mayorga, 2008, p. 81)

Pero si la mexicana Silvia Blanco alcanza a re-armar su identidad, la historia de Devendra Canchi, emigrante bengalí, constituye el ejemplo en sentido contrario: a pesar de que conoce el idioma y do- mina el oficio de la escritura (es un aprovechado estudiante de literatura en la Universidad de Vancouver), no logra comunicarse, ni puede construir una narración de sí mismo que lo satisfaga. Puesto que su acento extranjero era objeto de burlas, decidió no hablar; su vida social "real" derivó en un fracaso, todo lo contrario del personaje que representaba en su vida "virtual":

\footnotetext{
En los videojuegos fue el bengalí más asiduo y ganador competo de toda prueba que le pusieran por delante. En uno de sus videojuegos tenía que completar misiones. La primera era robarse un carro y matar al conductor a navajazos, la segunda era robar un banco con el carro robado y matar a la cajera a tiros, la tercera misión era la más difícil puesto que tenía que comprar un perro, encariñarse y después matarlo a machetazos y comérselo [...]. Obtuvo el puntaje más alto en el videojuego y empezó a tener admiradores en el Internet por su desempeño. Lo adoraban por matar. Esto es verdad también. (Mayorga, 2008, p. 29)
}

Devendra Canchi estaba roto y pese a que su oficio eran las letras - no logró articular con éxito memoria alguna que recompusiera los fragmentos. "Esa ‘introducción' de sentido [en la narración propia] ha sido llamada 'construcción de la identidad'. El peregrino y el mundo semejante al desierto por el que camina adquieren su sentido juntos, y cada uno a través del otro." (Bauman, 1996, p. 46) También podría decirse que el sentido que Canchi logró articular fue, precisamente, el de la búsqueda de la destrucción: en ella se encontró y se clausuró. Dice el narrador, del emigrante Canchi: "empezó a escribir lo más que pudo en sus clases de narración creativa. Primero poemas que no eran tan malos, pero que tenían un talante violentísimo. Yo he leído 
un par de estrofas y no puedo pasar de la segunda (uno debe ser muy valiente para poder leer la poesía de Devendra Canchi). Como proyecto de su clase, debía escribir dos obras de teatro y escribió solamente una de un solo acto. [...] A estas obras no las he leído completas y ni quiero saber cómo terminan" (Mayorga, 2008, p. 30)

El final de la vida de Devendra fue una performance, escrita con sangre en las aulas de la universidad: en el mismo tono, con la misma estética del ensañamiento, de la inestabilidad y la fragmentación. El día de la matanza de sus treinta compañeros, mostró la frialdad usual, similares parsimonia y cálculo de su rutina; realizó incluso una lista previa de sus actividades: "Matar a todos los ocupantes del edificio T; comprar vaselina; suicidarme" (Mayorga, 2008: 32). Y lo cumplió todo, manteniéndose hasta la última escena en la ruptura y las narrativas desbordadas. Pero estos rasgos de Devendra no son exclusivos de él; formarían parte de una común "manera de estar" en el mundo posmoderno: Zigmunt Bauman recuerda que, si la modernidad fue un tiempo signado por la búsqueda imperiosa de la firmeza y la identidad, la preocupación posmoderna se afinca sin denuedo en la no-permanencia: "La modernidad construía en acero y hormigón; la posmodernidad construye en plástico biodegradable”. (1996, p. 41)

Otro cuento de Mayorga, "Los dos amigos”, narra la vida del bávaro Hans y del alemán Mich; ambos nómadas, cada uno había recorrido diversos países de Europa antes de juntarse y de montar un espectáculo circense de magia y domesticación de felinos. Trabajaron en transatlánticos, casinos, cabarets y teatros, de diferentes categorías, hasta que uno de ellos falleció. En la historia de esos personajes encontramos hálitos del turista y el jugador, representaciones empleadas por Zigmunt Bauman para reflexionar sobre los contrastes entre la vida moderna y la posmoderna: "Así como el peregrino fue la metáfora más adecuada para la estrategia de la vida moderna preocupada por la sobrecogedora tarea de la construcción identitaria, el paseante, el vagabundo, el turista y el jugador proponen en conjunto, a mi juicio, la metáfora de la estrategia posmoderna, motorizada por el horror a los límites y la inmovilidad". (1996, p. 53) En la construcción de los personajes, en la historia y en la estética es posible identificar una tesitura que rompe con los afanes miméticos del realismo decimonónico:

El tono bufo [del narrador] no cambia al describir el ataque y muerte de Mich, por el tigre del espectáculo. El leit-motif del cuento es lo borroso de los límites que separan a la realidad de su representación: "El tigre se metió por detrás del escenario con Mich colgando (cual fantoche) de su hocico el público estalló. Y a pesar de que el estropicio era rojo y abundante en el escenario, aplaudieron harto, largo y tendido". Resaltan el culto fetichista del espectáculo y la mascarada, la teatralización, la pérdida de las nociones del horror y del valor de la vida. (Rodríguez, 2011, p. 12)

Es la visión posmoderna, representada en personajes jugadores, turistas y vagabundos.

Con ello, finaliza este ensayo. Se ha revisado algunos elementos de la literatura del narrador Esteban Mayorga: aspectos centrados en la auto-construcción del escritor, en la bifocalidad del narrador, y en la representación de los conflictos identitarios de los personajes migrantes. En este ensayo, más que la perspectiva estética, me ha interesado leer la escritura de Mayorga como una "práctica transnacional de intercambio y comunicación", a la luz de conceptos de la Teoría de la Globalización. 


\section{Bibliografía}

Appadurai, Arjun (2001a). "Aquí y ahora". En La modernidad desbordada. Dimensiones culturales de la globalización: pp. 17 -

38. Buenos Aires: Fondo de Cultura Económica de Argentina.

(2001b). "Paisajes étnicos globales apuntes e interrogantes para una antropología transnacional". En La modernidad desbordada. Dimensiones culturales de la globalización: pp. 63-79. Buenos Aires: Fondo de Cultura Económica de Argentina.

Bauman, Zygmunt (2003) [1996]. "De peregrino a turista, o una breve historia de la identidad". En Cuestiones de identidad cultural, Stuart Hall (comp.): pp. 40-68. Buenos Aires: Amorrortu.

Devés Valdés, Eduardo (2000). "Introducción". En El pensamiento latinoamericano en el siglo XX. Entre la modernización y la identidad. Tomo 1. Del Ariel de Rodó a la CEPAL (1900-1950): pp. 15-21. Buenos Aires / Santiago de Chile: Biblos / Centro de Investigaciones Diego Barros Arana.

Hall, Stuart (2002). "Political Belonging in a world of multiple identities". En Conceiving Cosmopolitanism. Theory, Context and Practice, pp. 25-32. Steven Vertovec y Robin Cohen (edits.). Londres / Nueva York: Oxford University Press.

(2003) [1996]." ¿Quién necesita identidad?" En Cuestiones de identidad cultural, Stuart Hall (comp.): pp. 13-39. Buenos Aires: Amorrortu.

Hartley, John (1995). "Posmodernismo". En Tim 0'Sullivan y otros, Conceptos clave en comunicación y estudios culturales, Buenos Aires, Amorrortu.

Hutcheon, Linda (1988). A Poetics of Postmodernism: History, Theory, Fiction, New York / London: Routledge.

Levitt, Peggy and Nina Glick Schiller (2004). "Conceptualizing Simultaneity: a Transnational Social Field Perspective". En International Migration Review, Vol. 38, No. 3 (Fall 2004): pp. 1002-1039.

Mayorga, Esteban (2008). Un cuento violento. Quito, El Conejo.

(2010). Vita frunis. Quito: Ministerio de Cultura del Ecuador.

(2012). Entrevista realizada por Martha Rodríguez Albán, a través de correo electrónico. Quito / Boston, mayo de 2012.

Moraga R., Jorge (2012). "Hannerz y Appadurai: la transnacionalidad ¿anda suelta?" Revista de Ciencias Sociales (Cl), (28) [fecha de Consulta 10 de Septiembre de 2019]. ISSN: 0717-2257. Disponible en http://www.redalyc.org/articulo.oa?id=708/70824554012

Rodríguez Albán, Martha (2011). "Modernidad narrativa y posmodernismo en el cuento ecuatoriano de entresiglos (19912010)". Ponencia presentada en el XI Encuentro sobre Literatura Ecuatoriana Alfonso Carrasco Vintimilla, celebrado en Cuenca, del 18 al 22 de octubre de 2011.

Shaw, Donald L. (2003) [1981]. "Hacia el posmodernismo", en Nueva narrativa hispanoamericana. Boom. Posboom. Posmodernismo: pp. 325-377. Madrid, Cátedra.

Vertovec, Steven (2004). "Migrant Transnationalism and Modes of Transformation". En International Migration Review Vol. 38, No. 3 (Fall 2004): pp. 970-1001. 